This is the author's final, peer-reviewed manuscript as accepted for publication. The publisher-formatted version may be available through the publisher's web site or your institution's library.

\title{
Understanding students resistance as a communicative act
}

Jeong-Hee Kim

\section{How to cite this manuscript}

If you make reference to this version of the manuscript, use the following information:

Kim, J.H. (2010). Understanding students resistance as a communicative act.

Retrieved from http://krex.ksu.edu

\section{Published Version Information}

Citation: Kim, J. H. (2010). Understanding student resistance as a communicative act. Ethnography and Education, 5 (3), 261-276.

Copyright: Copyright ( Taylor \& Francis Group, LLC

Digital Object Identifier (DOI): DOI: 10.1080/17457823.2010.511349

Publisher's Link: http://www.informaworld.com/openurl?genre=article\&issn=1745-7823 \&volume $=5 \&$ issue $=3 \&$ spage $=261$ 
Running Head: The Meaning of Student Resistance

Understanding Students Resistance as a Communicative Act

Jeong-Hee Kim, Ph.D

Assistant Professor of Curriculum Studies

Department of Curriculum \& Instruction

College of Education

Kansas State University

357 Bluemont Hall

1100 Mid-Campus Drive

Manhattan, KS 66506 U.S.A

Phone: 785-532-6976

Fax: 785-532-7304

E-mail: jhkim@ksu.edu 


\title{
Rethinking Resistance Theory under Zero-Tolerance Policies: The Meaning of Student Resistance as a Communicative Act
}

\begin{abstract}
In the current era of "zero tolerance", disciplinary practices including punishment, expulsion, physical and psychological surveillance, and confinement, are a major part of resistant students' lived experiences. This article is an ethnographic study of student resistance that is observed in an alternative high school in the U.S., which serves students expelled from regular schools for their acts of resistance. The purpose of this study is to explore how understanding of the meaning of student resistance can be used as a theoretical and pedagogical medium with which teachers can create an equitable, educational milieu that upholds views and experiences of the marginalized students. The study also offers a new insight into resistance theory drawing upon Dewey's transactional theory of resistance as a communicative act to further suggest what might be possible for the teachers and students to transcend conflicts in order to establish a more meaningful teacher-student relationship, moving beyond zero-tolerance policies.
\end{abstract}




\section{Introduction}

\section{Patience is the virtue that I have never learned. (Michelle, ninth grader)}

Michelle appeared to be stubborn, outspoken, and unruly. She was also smart and articulate, and had a strong sense of self. She was a typical student at Borderlands Alternative High School (pseudonym), who frequently showed acts of resistance enduring the consequences of being "kicked out" of the classroom. During an interview with her, she told me that patience was the virtue that she had never learned, therefore she was not going to be patient with teachers, especially those who did not make sense to her.

Michelle is one example of resistant students at Borderlands, and perhaps in any other school, as student resistance is ubiquitous in every school, not just in Borderlands. It seems that no matter what control a school exercises to suppress student resistance, resistance does not disappear. Schools make constant efforts, either implicitly or explicitly, to mitigate student resistance to school norms, rules, regulations, power, and control under the name of "zero tolerance". Zero tolerance policies, originally derived from the 1994 Gun-Free Schools Act, used to require suspension or expulsion only for a specified list of serious offenses, but they have been extended to include resistant acts or even minor behavioral issues, implemented as an overarching approach toward discipline. Recently, the U.S. Department of Education (2004) reported that over 50 percent of public schools took a serious disciplinary action in which more than 1,000,000 students were suspended or expelled in the 1999-2000 academic year. Reasons for the disciplinary action included not only possession of a gun but also a range of behavioral infractions such as fighting; refusal to obey a school rule and authority; possessing drugs; 
bullying or sexual, verbal harassment.

Although the goal of zero-tolerance polices is to secure a safe school environment for the well-being of the students, overreliance on zero-tolerance policies has caused more harm than benefits to students as it often results in antidemocratic and unfair actions including racially discriminatory sanctions (Skiba, 2000). It further legitimizes teachers and school administrators to find a "quick and easy" solution to a complex problem without exercising deliberation and critical judgment about what is best for the students (Giroux, 2003). In this disciplinary context, educators' compassion and understanding give way to rigidity and intolerance while adolescents or young people are "criminalized" or "demonized" (Giroux, 2003, p. 554), sending a message that they are dangerous, thus requiring constant surveillance and more strict enforcement of rules and regulations. Teachers and school administrators tend to choose to punish students rather than listen to them and work with them in order to provide meaningful educational experiences. In the mean time, resistant students are subject to frequent academic failure, grade retention, and negative school attitudes while being labeled as "slow learners," or "at-risk students" and blamed for their own school failure (Valencia, 1997).

Then, it is important that student resistance be critically examined for pedagogical considerations to promote an equal and equitable education. I write this article in hopes that understanding the concept of resistance would offer a way to transcend zero-tolerance policies; a way to listen to and communicate with resistant students to help them succeed in schools. More specifically, the purpose of this ethnography conducted in a public alternative high school in the U.S., is to explore how the meaning of student resistance can be used as a theoretical and pedagogical medium with which teachers can create an equitable educational milieu that upholds views and experiences of resistant students. The study also offers a new insight into resistance 
theory drawing upon Dewey's transactional theory of resistance as a communicative act to further suggest what might be possible for the teachers and students to understand conflicts and tensions in order to establish a more meaningful teacher-student relationship moving beyond zero-tolerance policies.

Now I turn to the review of the literature on theories of resistance drawing upon two different fields of education to address the complex nature of resistance, followed by description of the research site and methodology.

\section{Theories of Resistance}

Resistance theories emerged in the last several decades from neo-Marxist examinations of power struggles. They have raised important ideas for educators as they seek to reveal the degree to which the student's resistant behavior is associated with their struggle against domination (Knight Abowitz, 2000). In education research, the concept of resistance is used to explain various student behaviors occurring in schools that indicate the existence of tensions and conflicts between school, students, and the wider society to which students belong (Alpert, 1991; Lindquist, 1994). Therefore, the discussion of the concept of resistance or resistance theory is important in that it can serve as a means to address the complexity of the individual's experience of educational reality and the production of meaning. It can be used to explain the complicated reasons why and how marginalized students and groups in schools are being silenced and invisible within the educational system. Further, it explains why some students speak up or act out regarding their status, treatment, or relative position in the institution (Langhout, 2005). However, several studies point out that the concept of resistance is slippery and can be problematic (see Knight Abowitz, 2000; Lindquist, 1994; Olafson \& Field, 2003). Then, it would be important to take a close look at resistance theories in order to help the reader clearly 
conceptualize the concept of resistance.

Resistance theories have been developed in two different educational fields: the sociology of education and educational psychology. In the sociology of education, it is neoMarxists who developed a theoretical framework on resistance by criticizing Marxist perspectives on cultural and economic reproduction. Scholars associated with the Center for Contemporary Cultural Studies at Birmingham University in England, including Willis (1977), and critical theorists such as Apple (1982) and Giroux (1983) in North America criticized Marxist perspectives, mainly, correspondence theory. Correspondence theory explains how schools assimilate students into the capitalist economic order. For example, cultural reproduction theorists (e.g., Bowles \& Gintis, 1976) argued how schools reproduced the status quo by educating students corresponding to their economic status through the daily experience imposed by school authority. Neo-Marxists pointed out how this cultural reproduction theory ignored the fact that students and others, in some cases, actively resisted accepting their social status as prescribed by the economic order. That is, human agency or the ability to determine one's own action, was unexamined by cultural reproduction theory. Thus, directly influenced by Paulo Freire (1973), neo-Marxists developed a resistance theory centered on notions of human agency. They focused on cultural production rather than reproduction in which students and teachers were conceptualized as active agents who could negotiate, reject, or change the system. By attending to how students produce meaning and culture through their own resistance, critical theorists emphasize the role that students and teachers could play in challenging the structural aspects of schools. In brief, they counter the reproduction theory that schools and teachers serve to reproduce the existing status quo and pay more attention to the role of human agency, resistance, and contestation. 
However, postmodern and poststructual movements offer critiques on both Marxist and neo-Marxist notions of class-based structures as the absolute basis for resistance theorizing (Knight Abowitz, 2000). Postmodern feminist theorists, e.g., Ellsworth (1989), Lather (1991), and McRobbie (1991), criticized the male-oriented ethnographic work on resistance and argue for a view of power, subordination, and resistance inclusive of girls and women. Other resistance theorists e.g., Mac an Ghaill (1989) and McFadden (1995), focused on race and ethnicity in explaining how students' resistance to the demands of teachers and schools is not class based. They questioned the neo-Marxian notion of resistance, which regarded resistant acts as "forms of intentional opposition to the structure and function of schooling" (Grahame \& Jardine, 1990, p. 283) and extended sociological conceptions of resistance to include a notion of "play" (Grahame \& Jardine, 1990), “game playing” (Foley, 1991), or ritual performance (McLaren, 1994).

In educational psychology, the discussion of resistance theory is somewhat similar to the sociology of education, but it centers more on the kind of a function resistant acts play in students' lived experiences. Robinson and Ward (1991), for example, make a clear distinction between resistance for survival and resistance for liberation. Resistance for survival includes potentially destructive elements that young African American women may choose as strategies for short-term solutions such as early and unplanned pregnancies, substance abuse, school failure and food addictions. This kind of resistance can be facilitative, working to serve the institutional goals and socialization agendas (Ashforth \& Mael, 1998). Resistance for survival, then, is similar to the concept of resistance that Willis (1977) in the sociology of education found in the lads' oppositional behavior, which was for survival but also facilitative in that resistance of workingclass boys to hegemonic ideology and power ironically helped to reproduce the existing status quo rather than challenging it. 
Resistance for liberation, on the other hand, refers to resistance that may lead black girls and women to acknowledge the problems of an environment that oppresses them, and in turn, to transform them to self-conscious agents (Robinson \& Ward, 1991). According to Robinson \& Ward, this kind of resistance is "healthy" because it helps adolescents, and black adolescent females in particular, move beyond the pathological models that focused on the perspective that “the psychosocial experiences of African American teens are inherently disordered and unhealthy" (p. 88).

In a similar vein, Brown and Gilligan (1992) conducted a longitudinal study to describe the psychological parameters and the developmental or educational implications of female adolescents' struggles. They make a distinction between psychological resistance and political resistance. The former refers to times when a person buries her feelings and thoughts and manifests confusion, uncertainty, and dissociation; and the latter refers to times when people struggle against abusive relationships and fight for relationships in which they can openly disagree with others, feeling safe for speaking up. While acknowledging the ambiguity between psychological resistance and political resistance, Brown and Gilligan (1992) contend how these two types of resistance intersect and can be helpful and healthy for adolescents to overcome losses and despairs that are psychologically wounding. They state:

The tendency for a healthy resistance to turn political and for a political resistance to turn into a psychological resistance becomes central to our understanding of the difficulties and psychological suffering that many of these privileged or fortunate girls experience. At adolescence, we saw women's psychological development becoming inescapably political. (1992, p. 16)

As such, a healthy resistance is liberating and political as well as psychological; it makes 
students cognizant of social and cultural contexts that are debilitating.

Thus far, I have briefly summarized resistance theories drawing upon two academic fields, the sociology of education and educational psychology. As shown above, these theories parallel but often intersect with each other sharing some commonalities that have implications for teaching and learning. While educational sociologists focus on explaining why the opposition of some groups against others is politically and morally necessary in social institutions (Knight Abowitz, 2000), educational psychologists focus on examining individual resistance that takes place developmentally in the process of identity formation (see Brown \& Gilligan, 1992; Langhout, 2005; Miron \& Lauria, 1995; Robinson \& Ward, 1991). However, both fields view resistance as struggles interwoven in everyday life influenced by gender, race, class, and sexuality, and provide the body of knowledge that contributes to our understanding of tensions and conflicts that take place in schools.

Then, how do we utilize resistance theories to better understand the growing disciplinary practices under zero-tolerance policies? Can we use the notion of agency that works for social change to the current context of increasing suspensions and expulsions? Some researchers criticize resistance theories by pointing out how they romanticize the concept of resistance (Walker, 1986; Roman \& Christian-Smith, 1988) and others contend that resistance theories fail to address the complexity of agency that leaves little hope for social transformation (Senese, 1991). Knight Abowitz (2000) also posits that contemporary resistance theories too often perceive resistance to be a causal reaction that takes place during interaction between two independent entities, i.e., between the teacher and the student, without allowing a possibility of collaboration between them. She further argues that "what remains to be understood in more depth, however, are the ways in which resistance, as a communicative act, is interpreted by 
educators as well as researchers, and accordingly assigned meaning within school settings" (p. 878). Then, it seems that we need a more holistic view of resistance to understand tensions and conflicts that occur in the current zero-tolerance context in order to provide a meaningful education for the disenfranchised students. I will explore this view in the next section.

\section{Toward the Transactional Theory of Resistance as a Communicative Act}

Drawing upon Dewey's transactional theory of inquiry, Knight Abowitz (2000) encourages educators to broaden and deepen the inquiry into opposition and resistance and to more fully examine relevant actors and contexts, calling for the idea that resistance is an act of communication, that is, a "means of signaling and constructing new meanings" (p. 877). Dewey and Bentley (1949) posited three modes of inquiry: self-action, inter-action, and trans-action. Self-action is an inquiry in which things are viewed as acting under their own powers, while inter-action is another inquiry of a type in which a thing is balanced against another thing in causal interconnection (p. 108). Trans-action, on the other hand, is inquiry of a type in which "existing descriptions of events are accepted only as tentative and preliminary, so that new descriptions of the aspects and phases of events, whether in widened or narrowed form, may freely be made at any and all states of the inquiry" (p. 122). This transactional approach to an inquiry, according to Dewey and Bentley, is "the seeing together, when the research requires it, of what before had been seen in separations and held severally apart" (1949, p. 112). Therefore, for Dewey and Bentley, transactional inquiry is the most encompassing mode of inquiry that questions the complex nature of human encounters and human knowing.

Here are some examples of how these three modes of inquiry can be applied to explain the students' acts of resistance. If we view students who are expressing his/her identity of style (clothing, language) and resistant behavior (cutting class, talking back, breaking school rules) 
from an inquiry of self-action, we understand them as acting out their identities that are internal and unchanging, e.g., their ethnicity, gender, or low socio-economic status. Therefore, from the perspective of self-action, students' school failure is attributed to their cultural differences, thus legitimize the "blame the victim" ideology (Valencia, 1997). On the other hand, a mode of interaction views that opposing cultures that exist in the school, e.g., a culture of authority and student subculture, are inherently contradictory and clash as a causal effect. In this view, the teachers represent a culture of authority that holds legitimated knowledge; the student subculture represents a culture of opposition and unofficial, marginalized knowledge (Knight Abowitz, 2000). When these two cultures interact, the legitimacy of the authority remains unchanged, which imposes on the student subculture and causes student resistance. Although the interactionist view is somewhat advanced from the view of self-action, it still represents a closed system of two opposing cultures that do not change and it does not take into consideration other factors in the social context.

Finally, in the transactionalist view of resistance, tensions and conflicts are viewed more holistically recognizing how multiple facets of an event are intertwined. That is, each opposing culture is perceived as an organic, living, complex entity that is in the process of evolving through the tensions in the socio-economic, historical, and racial context. Hence, the encounters between authority figures and the student culture are understood "not simply as oppositional but as shaping both future encounters and the nature of the conflict itself' (Knight Abowitz, 2000, p. 883), (re)constructing the ongoing relationship between the teachers and the students.

The importance of the transactional mode of inquiry resides in that, according to Dewey (1916), it necessitates communication through which the parties involved, e.g., teachers and students, can modify their views on the conflicting condition. Dewey defines communication as 
the "sharing of experience which modifies the disposition for both parties" (Dewey, 1916, p. 9) who engage in the experience. He further contends:

To be a recipient of a communication is to have an enlarged and changed experience. One shares in what another has thought and felt and in so far, meagerly or amply, has his own attitude modified. Nor is the one who communicates left unaffected. (Dewey, 1916, p. 5) Hence, transactionalistic inquiry promotes communication and offers a perspective on resistance that "can help frame opposition in more communicative terms, thus enhancing the practical capacities of educators to respond to resistance in ways that enhance its coordinating, communicative potential" (Knight Abowitz, 2000, p. 883). With this view, teachers can not only seek to understand student resistance as an act of meaning-making, but use the inquiry into student resistance as a springboard to question their own classroom practices.

\section{Research Methods and Methodology}

This ethnography is a case study which concentrates on experiential knowledge of the case (Borderlands Alternative High School) and pays close attention to its activities and phenomena that are going on in the case (Stake, 2005). An ethnographic study requires the researcher to both observe and participate in the field of study. In this sense, ethnography became "privilege" (Tsolidis, 2008), which allowed me to explore resistant acts holistically in relation to the school context placed in extended time and space while examining implicit assumptions that I as a researcher might take for granted. I immersed myself into the school setting Monday through Thursday for five months from August through December 2003, six hours each day for the fieldwork.

Data were collected by means of observation, participant observation, interviews, informal talks, and school documents. For classroom observation, I observed mainly Ms. 
Hardy's 9th grade class (all the participants' names are pseudonyms) and Mr. Wright's $10^{\text {th }}$ grade class although I observed six other classes when Ms. Hardy's and Mr. Wright's classes were not in session, in order to get a better sense of the school community as a whole. I was not only in classrooms but also in faculty meetings, monthly assembly, school events such as the Halloween party serving food to students, and Christmas community service plans. As a participant observer, I took part in classroom activities, tutored students who were struggling in math and reading, and interacted with both students and teachers everyday. Due to this active engagement, I was soon accepted as a part of the school community. Students invited me to sit with them during lunch hours in which most of our informal conversations took place.

My main approach to the fieldwork was "conversation as research" (Kvale, 1996) in which conversations about school experiences and daily life with students and school staff took place. This approach helped me not only to build informal relationships with each member of the school community, but also to understand the ways the structure of the school worked and how the school was perceived by students. Through this approach, a level of familiarity and comfort were developed, which encouraged the students and teachers to feel comfortable talking to the researcher. Detailed summaries of the conversations were recorded in field notes at the end of each day (Kvale \& Brinkmann, 2008).

I had nine interviews with students and staff, which consisted of semi-structured, openended questions. I took an "empathetic approach" to the interviews, "an ethical stance in favor of the individual or group being studied" (Fontana \& Frey, 2005, p. 696). The principal, school security guard, a ninth grade teacher (Ms. Hardy), two ninth graders (Michelle \& Corsica), and one eleventh grader (Kevin) were interviewed individually during their school hours. The student participants were recommended by their teachers who believed that these students displayed 
resistant behavior more frequently than others. Students (Michelle, Corsica, and Kevin) were interviewed twice. Most interviews lasted about an hour and a half while a couple of follow-up interviews for students lasted about an hour. Interviews were tape-recorded and then transcribed by me. The interviewees were asked to talk about their backgrounds, views on the alternative schooling, and their school experiences. While interviews with the school staff provided insights into the school structure as to how the school works, interviews with the students provided insights into their attitudes and perceptions of the school and the teachers. Another data set was students' homework materials, school policy handbook, and teaching materials. These different data sets were analyzed and triangulated against each other for the identification of emerging themes.

\section{Research Site: Borderlands Alternative High School}

Before discussing the research site, I will first explain what an alternative school is in the U.S context. Each state has different definitions of alternative schools. In case of Arizona where the current study took place, the Arizona Department of Education first announced formal definitions of alternative schools in 1999. According to the Arizona Department of Education (1999), alternative schools are defined as those that exclusively serve students in one or more of the following categories: students with behavioral issues, students identified as dropouts, students in poor academic standing who are more than one year behind on academic credits, or who have a demonstrated pattern of failing grades. Pregnant and parenting students, and adjudicated youth are also included.

Borderlands Alternative High School is a public school for students from 9th through 12th grade. It accepts students only by referrals from principals of regular schools. The school opened in 1999 and its enrollment has increased every year since then. 152 students enrolled at 
Borderlands during the 1999-2000 school year, 291 students during the 2000-2001, and 350 students during the 2001-2002 school year.

According to the school handbook, student ethnicity during the 2001-2002 school year was comprised of 73\% white, Non-Hispanic; 18\% Hispanic origin; 3\% black, non Hispanic; $4 \%$ American Indian, Eskimo; and 2\% Asian and Pacific Islander. Borderlands showed a slight increase in the percentage of students from minority backgrounds over the past three years. Initially, $13 \%$ of the student population came from minority backgrounds, but now $27 \%$ come from these backgrounds. The school principal informed me that most of the students are from low-income families and many of them are living with a single parent. The school security guard commented in sympathy, "These kids have a lot of baggage" meaning that students had to deal with many personal issues besides schoolwork. The school's dropout rate has been relatively high. For example, 350 students (105 females and 245 males) were enrolled at the start of the 2001-2002 school year, but only 157 (45\%) remained at the end of the year. Students are disciplined based on the school's zero-tolerance policies. See Table 1 for a specific list for disciplinary referrals that the school received during the 2001-2002 school year.

\begin{tabular}{|l|c|}
\hline \multicolumn{1}{|c|}{ Disciplinary Reasons } & Number of Students \\
\hline Misbehavior on a school bus & 19 \\
\hline Defiance & 35 \\
\hline Disorderly conduct & 29 \\
\hline Possession of drugs & 17 \\
\hline Tobacco smoking & 50 \\
\hline Harassment & 12 \\
\hline Speech offences & 41 \\
\hline Unexcused absences & 51 \\
\hline Violating dress codes & 13 \\
\hline $\begin{array}{l}\text { Assault, gang activity, theft, trespassing, } \\
\text { and vandalism }\end{array}$ & The remainder \\
\hline
\end{tabular}

Table 1. List for Disciplinary Referrals at Borderlands (2001-2002)

Students are accepted by referral, not by their choice, as reflected in the school 
principal's statement below:

We surely are a referral school. Students cannot choose to come here. They just can't walk in off the street or drop from high school and come here. They have to have a referral from their principal. There has to be a behavioral reason. Our superintendent said, 'your school will be a referral basis only.' We have a tougher year this year behaviorally, but we are making great strides.

As the principal mentions, students are referred by the principals of regular schools mainly due to "behavioral reasons".

Students are enrolled for a half-day at Borderlands; during the other half of the day, they are required by the school district to take either career explorations, service learning, or other courses at a local institute of technology such as auto mechanics, cosmetology, photography or other vocational classes. Students can also receive high school credit hours for working at McDonald's or other local stores. Each grade has two classes and two teachers, with a total of eight grade teachers. Each class has an enrollment of about 15 students, but there are usually 5 to 8 students attending the class. The largest classes are 10th grade English and Social Studies with about 10 to 13 students.

\section{Understanding the Meaning of Student Resistance as a Communicative Act}

For data analysis, I employ Dewey's transactionalist view of resistance

as an encompassing theoretical framework while incorporating other resistance theories reviewed above. I have identified three themes that emerged from the data ${ }^{1}$. These themes are: resistance as a way of self-defensive mechanism; resistance as a way of demanding a meaningful instruction; and resistance as a way of affirming their agency and thus empowering themselves.

\section{(1) Resistance can be communicated as a self-defensive mechanism}

The first theme that emerged is resistance as a self-defensive mechanism. One commonly

${ }^{1}$ For the purpose of this paper, I focus on overt resistant behavior although it should be noted that resistant behavior is not always overt or explicit. Students may express resistance in various ways such as silence or non-participation. See, for example, Alpert (1991); Quigley (1987). 
observed resistant act as a self-defensive mechanism is a refusal to learn, what Kohl (1994) calls, "not-learning" strategy. Adolescents frequently adopt this strategy because it makes them at least function on the margin of society instead of falling into total disaster. An example comes from the following dialogue I had with Juan in the 9th grade social studies class where students were filling out a worksheet that was about Chinese philosophy. When I looked at Juan's worksheet, the answers he put on the worksheet did not make sense. With an intention to help him, I asked:

Researcher: Do you think your answers are right?

Juan: Who cares? I don't want to learn this crap! This is so stupid. I don't want to learn this stupid crap.

Then, he continued filling out the worksheet with words that did not make sense. The way he said "I don't want to learn this stupid crap" and the fact that he repeated it again indicate how determined he was to NOT learn the material that was presented to him. This "not-learning" strategy or resistance to learn, could be viewed as a cause that puts Juan behind academically. But it can be viewed "healthy" in that it helps Juan avoid to think he is not smart enough to learn the material. In other words, this disengagement of learning is in fact an act of resistance (Brown \& Gilligan, 1992), through which students try to communicate their self-defensiveness as a way of finding an alternative solution that prevents them from falling into total disaster or failure (Kohl, 1994).

In another example, Corsica, African American girl in ninth grade, "talks back" to the teacher to defend herself by disagreeing with the teacher's comment. At that time, Corsica was upset at Nancy because Nancy threw her Gatorade bottle into the garbage can by mistake. When Corsica was having an argument with Nancy, Ms. Hardy stopped Corsica.

Ms. Hardy: Corsica, stop it! You always bitch about something everyday. Corsica: No, I don't! There are days when I don't say even a word! Ms. Hardy: Come here! You're not supposed to talk back to me. You have to go to the 
office. Let's go!

(After that, Corsica was not allowed to go back to the classroom. Instead, she was ordered to stay in the office until her guardian came to pick her up.)

In this case, Corsica could or should not have said anything in order to avoid the suspension. But it seems that it was more important for Corsica to defend herself than avoiding the punishment. Corsica defended herself by pointing out that the teacher was wrong about her. The teacher reacted to Corsica's "talking back" by suspending her immediately without considering why. Later, Ms. Hardy told me that Corsica was living in a group home and she was very emotional since her foster mom gave her up and sent her to the group home. Ms. Hardy seemed to believe that it was that family issue that caused Corsica's resistance, not what Ms. Hardy had told Corsica.

Resistance can be a way of communication that students express to protect themselves from threats or punishments that come from the school authority, teachers, and the school environment. It may be one of students' survival strategies that keep them from internalizing learned helplessness that may otherwise lead them to think of themselves as a failure. Learned helplessness occurs when a student has been conditioned to believe that educational failure is unavoidable, which prevents future learning (Webb, 1989). As a self-defensive mechanism, resistance can ironically help students avoid such learned helplessness and may promote personal pride (Robinson \& Ward, 1991).

\section{(2) Resistance can be communicated as a way to demand a meaningful instruction}

The second theme that emerged is resistance as a demand for a meaningful instruction. It is typically understood that students disrupt the class or violate classroom rules because they are not interested in learning. But data shows that low-level, disengaging instruction may trigger 
student resistance. For example, rote memorization of discrete facts and filling-in blanks on a worksheet are typical classroom activities at Borderlands. Students mechanically copy the answers from a textbook. Lessons focus on "the basics" needed for the entry-level jobs while understanding the material is not encouraged. Students work on the same worksheet repetitively for a week before they take a test on it.

In $10^{\text {th }}$ grade Social Studies class, Mr. Wright said that his course would be the easiest one.

Mr. Wright : My class will be the easiest course you've ever taken. We'll learn definitions of terms and have quizzes on them. Mid-term and finals are word-byword from the quizzes... I don't know how else I can make the course easier for you than this.

Bill: (Cynically) Are we gonna do bunch of damn definitions again?

Mr. Wright: (No response. He continues talking about his course description.)

From the way Mr. Wright said it, he seemed to be a caring teacher as he said, "I don't know how else I can make the course easier for you than this". Mr. Wright's intention might have been to help students be motivated in coming to class. However, Bill's cynical response, “Are we gonna do bunch of damn definitions again?" implied how Bill felt about Mr. Wright's class and he was rhetorically challenging the teacher to provide more meaningful instruction instead of the “damn” definitions. From my observation, Mr. Wright's main instructional activity was to have students copy the definitions of terms from the textbook. Mr. Wright's class was quiet most of the time as each student was busy mechanically copying the definitions which would be on the test.

Another example comes from Ms. Hardy's class. Ms. Hardy teaches both ninth grade math and science. In her math class, students were learning to find the area of a triangle. There were five students: Travis, Eddie, Laurie, Corsika, and Michelle. They were eating chips making 
a crunchy noise (eating is allowed in this class) while working on questions from a handout.

Laurie started talking to Travis.

Laurie: Travis, pass me the chip bag.

(Travis hands it to Laurie.)

Ms. Hardy: Laurie, be quiet. Stop talking.

Laurie: Why? I already know this stuff. I learned it in 7th grade. I'm bored!

Ms. Hardy: Laurie, listen. Because you know the stuff, it doesn't mean that you can talk to others. They don't know the stuff, so they need to focus on this. Don't interrupt the class. (Ms. Hardy starts explaining a formula. Again, Laurie says something to Corsika who is sitting next to her.) Laurie, you don't listen to me. What did I just tell you? Get out! Take your purse with you. Don't come back. Everybody says bye to her. (One student says, "Bye $"$ ")

Laurie was challenging the teacher to explain why she had to stop talking. Laurie believed that she had a reason to talk: she was bored because she already knew the material. Would Laurie have continued to interrupt the class if Ms. Hardy understood Laurie's communication? That is, is it reasonable to think that Ms. Hardy could/should have understood Laurie's resistant behavior as a way to communicate her boredom in class and demanding a more meaningful class?

\section{(3) Resistance can be communicated as a way to affirm one's agency and self-}

\section{empowerment}

It is notable that adolescents in this study display resistant acts as a way to affirm their agency, thus empower themselves, which may facilitate them to think independently, create their own meaning, and find their own voice. This kind of resistance could be "the necessary tool to think critically about herself, the world and her place in it" (Robinson \& Ward, 1991, p. 89). Further, for some students, it could be the way "to make themselves heard and to define themselves as active participants in the world" (McLaren, 1994, p. 227). In this sense, resistance can be communicated as an effort to affirm the student's agency and self.

Michelle, for example, who said to me "Patience is a virtue that I've never learned", is frequently expelled from class for her resisting behavior. One day, in Ms. Hardy's class, she 
whistled after finishing her class assignment.

Ms. Hardy: (annoyed) Michelle, you're going to get a zero point today because you're whistling.

Michelle: (annoyed) What? I get a zero point even though I finished my assignment?

Ms. Hardy: Yes, you get a zero point for the day for interrupting the class by whistling.

Michelle: That's the stupidest thing I've heard! Well, if I'm getting a zero point for the day, I might as well keep whistling. (Michelle kept whistling.)

Ms. Hardy: Michelle, stop whistling right now! Otherwise, I'll send you to the office. (But Michelle continued to whistle. Ms. Hardy phoned the office and asked the security guard to come and get Michelle. Five minutes later, Michelle was taken to the office.)

It seems to be natural that Ms. Hardy asked Michelle to stop whistling. But Michelle did not understand why she was getting a zero point even though she finished her assignment. It did not make sense to her. So she would rather continue whistling based on her judgment. She resisted listening to the teacher exercising her agency, an ability to act upon her judgment. Michelle further confirms her "self-identity" at the interview and clearly indicates that her resistant act is an expression of self- affirmation and self-valuation. She says:

I am goofy. I don't care what others think about me. But at school, I get into trouble because of that. Teachers don't like my personality. Ms. Hardy said to me the other day, 'I don't like your personality. You need to stop acting out. You need to change your personality. Then, your school life will be a lot easier.' I was really upset. Why do I have to change my personality? I don't care if she likes it or not. I have my own opinions unlike other kids. But teachers think I'm acting out, disruptive, unruly, and rude. Because I like to speak up, I get kicked out of classroom all the time.

Ms. Hardy might have been trying to advise Michelle to change her personality so that Michelle could stop acting out, which could prevent Michelle from being expelled from class. However, Miron and Lauria (1995) note that student resistance, like acting out, is a "struggle for identity (self-definition) or what we shall call identity politics" (p. 30). Then, would it have been possible for Ms. Hardy to understand this "identify politics" as noticeable struggles commonly observed among students? Is it possible for us to understand Michelle's resistant act as a part of the 
process of identity formation and self-creation, claiming her agency? Moreover, how do we promote it as a pedagogical act?

Students may communicate through resistance to claim their agency and "stand up for" themselves against an oppressive situation, which empowers them to create a change in the situation. McWhirter (1991) defines empowerment as a process through which an individual or groups of people who lack power become aware of the power dynamics that operate in their lives. Through resistance, students can show their awareness of the power relations to challenge the status quo and the structural aspects of schools. Here is what Kevin, 17-year old senior, said at the interview:

This happened last year in Mr. Schond's class. Everybody was talking. But when I opened my mouth in class, Mr. Schond would send me out for no reason. He said, 'Kevin, go to the office!' When he said that to me again, I finally said, 'No, you can't send me to the office. The whole class is talking. Why do you punish only me, not others? Don't be like that!' So, Mr. Schond had to send the whole class to the office. He lost his job because of that.

According to Kevin, Mr. Schond had a reputation of losing his temper and treating students unfairly. Therefore, what Kevin's statement implies is that because he resisted and stood up for himself, Mr. Schond ended up getting fired and it was a good thing. Kevin resisted because he was treated unequally and his resistance created a change. Tensions and conflicts occur when people are treated unequally, hold subordinate positions, and are restricted from exercising their freedoms and rights (Turiel, 2003). Hence, resistance can work as a self-empowerment showing a sign of political resistance (Brown \& Gilligan, 1992), which is also associated with resistance for liberation in which students acknowledge the problems of an environment that oppresses them (Robins \& Ward, 1991). When we understand student resistance as a way to affirm one's agency and self-empowerment, we trust that students have a cognitive ability to work as active agents who can negotiate and communicate with teachers to create a change. 


\section{Discussions / Conclusion}

Thus far, I have explored what student resistance might mean and how the meaning of resistance can serve as a communicative act. By providing an ethnographic account of how student resistance can be understood and communicated, I argued for a new understanding of resistance from Dewey's transactional theory of resistance as a communicative act. Then, what implications does this view have in teaching and learning in the current era of zero tolerance?

Zero-tolerance disciplinary policies are implemented on the notion that they are for the safety and well-being of the majority of students, while protecting their educational rights from being violated by undisciplined classmates (Nelson, Palonsky, \& McCarthy, 2007). However, there is as yet little evidence that such disciplinary policies contribute to improved student behavior or overall school safety (Skiba, 2000). Rather, zero-tolerance polices are becoming a threat to all youth and to any notion of equal educational opportunity. Further, as students of color are overrepresented in the number of schools' disciplinary actions, zero-tolerance policies reinforce the image of students of color as "a source of public fears and a threat to public school safety" (Giroux, 2003, p. 562). In this context, more and more schools resemble prisons, creating a school to prison pipeline (Nolan \& Anyon, 2004) or an "adjunct of the criminal justice system" (Giroux, 2003, p. 562), where video surveillance cameras, electronic badges, patrolled cafeterias, routine backpack searches, and police officers wandering in the hall way have become part of the school landscape. Education has become synonymous with rigid disciplinary practices while trust and respect give way to fear and suspicion, having a detrimental affect on relationships between teachers and students.

Then, it is quite obvious that we have allowed ourselves to be oblivious of the aim of 
education through over-reliance on zero-tolerance policies in response to student resistance. Intolerance to students' resistant behavior has become the "rule of thumb", which calls for a better understanding of student resistance. Resistance theories that focus on a mode of self-action in which students' acts of resistance are viewed as "acting out", or a mode of inter-action in which resistance is viewed to challenge the authority that is imposed on the student, may help us understand why tensions and conflicts occur in schools. However, they do not sufficiently provide knowledge about how both teachers and students can work together to ameliorate the current oppressive school environment.

Hence, I argue for a new understanding of resistance from the transactional mode of inquiry as communication in which tensions are viewed more holistically and perceived as an organic entity that is in the process of evolving and becoming. The transactional theory of resistance as a communicative act opens up for dialogue and communication, inviting both teachers and students to work toward becoming "recipients of a communication" and thus to have "enlarged and changed experiences" (Dewey, 1916, p. 5) in public schools in general and alternative schools like Borderlands in particular. This view of resistance can be used as a theoretical and pedagogical medium with which teachers and students interrogate together to create an equitable school environment transcending conflicts and tensions, and moving beyond zero-tolerance policies. This, in turn, will create a new horizon of the relationship between the teachers and the students that is always in the process of evolving and becoming, hence working toward a more humane pedagogy. 


\section{References}

Alpert, B. 1991. Students' resistance in the classroom. Anthropology and Education Quarterly, 22(4): 350-366.

Apple, M. W. 1982. Education and power. Boston: Routledge and Kegan Paul.

Arizona Department of Education. 1999. Retrieved August 20, 2003, from http://www.ade.az.gov/azlearns/A7-AltvSchDefinition.pdf

Ashforth, B. E., \& Mael, F. A. 1998. The power of resistance: Sustaining valued identities. In R. M. Kramer \& M. A. Neale (Eds.), Power and influence in organizations. 89-119. Thousand Oaks, CA: Sage.

Bowles, S., \& Gintis, H. 1976. Schooling in capitalist America: Educational reform and the contradictions of economic life. New York: Basic Books.

Brown, L. M., \& Gilligan, C. 1992. Meeting at the crossroads: Women's psychology and girls' development. Cambridge, MA: Harvard University Press.

Dewey, J. 1916. Democracy and education. New York: The Free Press.

Dewey, J., \& Bentley, A. 1949. Knowing and the known. Boston: The Beacon Press.

Ellsworth, E. 1989. Why doesn't this feel empowering? Working through the repressive myths of critical pedagogy. Harvard Eduational Review, 59(3), pp. 297-324.

Foley, D. E. 1990. Rethinking school ethnographies of colonial settings: A performance perspective of reproduction and resistance, Comparative Education Review, 35, pp. 532551.

Fontana, A., \& Frey, J. 2005. The interview: From neutral stance to political involvement. In N. Denzin \& Y. Lincoln (Eds.), Handbook of Qualitative Inquiry (3 ed.). 695-728. Thousand Oaks, CA: SAGE Publications. 
Freire, P. 1973. Pedagogy of the oppressed. New York: Seabury Press.

Giroux, H. 1983. Theory and Resistance in Education: A Pedagogy for the Opposition. New York: Bergin and Garvey.

Giroux, H. 2003. Racial injustice and disposable youth in the age of zero tolerance. International Journal of Qualitative Studies in Education, 16(4): 553-565

Grahame, P. R. \& Jardine, D. W. 1990. Deviance resistance and play: A study in the communicative organization of trouble in class. Curriculum Inquiry. 20(3): 283-304.

Knight Abowitz, K. 2000. A pragmatist revisioning of resistance theory. American Educational Research Journal, 37(4): 877-907.

Kohl, H. 1994. "I won't learn from you" And Other Thoughts on Creative Maladjustment. New York: The New Press.

Kvale, S. 1996. InterViews. Thousand Oaks, CA: SAGE Publications.

Kvale, S., \& Brinkmann, S. 2008. InterViews: Learning the craft of qualitative research interviewing (2 ed.). Thousand Oaks, CA: SAGE Publications.

Langhout, R. D. 2005. Acts of resistance: Student (in)visibility. Culture \& Psychology, 11(2): $123-158$.

Lather, P. 1991. Getting smart: Feminist research and pedagogy with/in the postmodern. New York: Routledge.

Lindquist, B. 1994. Beyond student resistance: a pedagogy of possibility. Teaching Education, $6(2): 1-8$

Mac an Ghaill, M. 1989. Beyond the white norm: The use of qualitative methods in the study of black youths' schooling in England. International Journal of Qualitative Studies in Educaiton, 2(3): 175-189. 
McFadden, M. G. 1995. Resistance to schooling and educational outcomes: Questions of structure and agency. British Journal of Sociology of Education. 16(3): 293-308.

McLaren, P. 1994. Life in schools: An introduction to critical pedagogy in the foundations of education (2nd ed.). New York: Longman.

McLaren, P. 2003. Critical pedagogy: A look at the major concepts. In A. Darder, M. Baltodano \& R. Torres (Eds.), The critical pedagogy reader, pp. 81-102. New York: RoutledgeFalmer.

McRobbie, A. 1991. Feminism and youth culture: From Jackie to just seventeen. London: Macmillan.

McWhirter, E. H. 1991. Empowerment in counseling. Journal of Counseling and Development, 69: 222-227.

Miron, L. F., \& Lauria, M. 1995. Identity politics and student resistance to inner-city public schooling. Youth and Society, 27(1): 29-53.

Nelson, J. L., Palonsky, S. B., \& McCarthy, M. R. 2007. Critical issues in education: Dialogues and dialectics (6th ed.). New Yrok, NY: McGraw-Hill.

Nolan, K., \& Anyon, J. 2004. Learning to do time: Willis's model of cultural reproduction in an era of postindustrialism, globalization, and mass incarceration. In N. Dolby \& G. Dimitriadis (Eds.), Learning to labor in new times. 129-140. New York: RoutledgeFalmer.

Olafson, L., \& Field, J. 2003. A moral revisioning of resistance. The Educational Forum. 67(2): $140-147$.

Quigley, B. A. 1987. Learning to work with them: Analysing nonparticipation in adult basic education through resistance theory. Adult Literacy and Basic Education, 11(2): 63-71. 
Robinson, T. L., \& Ward, J. V. 1991. "A belief in self far greater than anyone's disbelief": Cultivating resistance among African American femal adolescents. Women \& Therapy, 11: 87-103.

Roman, L. \& Christian-Smith, L. (Eds.). 1988. Feminism and the politics of popular culture. London, England: Falmer.

Senese, G. 1991. Warnings on resistance and the langauge of possibility: Gramsci and a pedagogy from the surreal. Educational Theory, 41(1), pp. 13-22.

Skiba, R. 2000. Zero tolerance, zero evidence: An analysis of school disciplinary practice. Policy research report \#SRS2. Bloomington, IN: Indiana Education Policy Center. Retrieved September 2009 from http://www.indiana.edu/ safeschl/ztze.pdf.

Stake, R. 2005. Qualitative case studies. In N. Denzin \& Y. Lincoln (Eds.), Handbook of qualitative research (3 ed.). 443-466. Thousand Oaks, CA: SAGE Publications.

Tsolidis, G. 2008. The (im)possibility of poststructuralist ethnography: Researching identities in borrowed spaces. Ethnography and Education, 3(3): 271-281.

Turiel, E. 2003. Resistance and subversion in everday life. Journal of Moral Education, 32(2): $115-130$.

U.S. Department of Education. 2004. National Center for Education Statistics, Indicators of School Crime and Safey. Retrieved September 2009 from http://nces.ed.gov/pubs2005/crime_safe04/tables.asp.

Valencia, R. 1997. The evolution of deficit thinking: Educational thought and practice. Washington, D.C.: The Falmer Press.

Webb, R. B. 1989. Schooling and society. New York: Prentice Hall.

Walker, J. C. 1986. Romaticising resistance, romanticixing culture: Problems in Willis's theory 
of cultural production. British Journal of Sociology of Education, 7(1): 59-80.

Willis, P. 1977. Learning to labor: How working class kids get working class jobs (Revised ed.). New York: Columbia University Press. 